\title{
Global building environmental performance assessment systems and theirrole in environmental conservation: Developing an environmental performance assessment system for the Saudi environment
}

\section{ABSTRACT}

This paper discusses the principles of environmental performance for buildings and their direct effects on the depletion of environmental resources. The research is significant in proposing ways of reducing resource depletion and improving utilization by developing systems to assess buildings' environmental performance and their feasibility for environmental, sustainable, and conservation development. The paper introduces an assessment system that can measure the environmental performance of buildings aiming to make them more efficient and address their impact. It starts with the theoretical approach, focusing on two areas. The first discusses the concept of the environment, defining its terms, identifying the environmental components and problems encountered and discussing the extent of the effect on the quality of human life. The second discusses buildings' environmental performance, specifically their responsiveness and adaptation to the environment, studying the elements that influence the quality of buildings and their suitability given environmental and climatic conditions. The empirical analysis then examines and compares global environmental performance assessment systems-Leadership in Energy and Environmental Design (LEED), the Building Research Establishment Environmental Assessment Method (BREEAM), and the Pearl Rating System (PRS) — and usage methodology. The paper concludes by proposing a new environmental assessment system adapted to the study area to assess buildings, thus making a contribution to knowledge. 


\section{KEYWORDS}

Environment, Environmental performance, Internal environmental quality, Thermal comfort, External factors, Environmental performance measurement systems.

\section{INTRODUCTION:}

Environmental protection and preservation are currently a major international priority because of the direct effects of the environment on the quality of human life and behavior. This has led many countries to develop strategies to protect the environment from potential harm. International efforts have led to the development of many concepts related to environmental architecture, exploiting the engineering and technical potential of environmental conservation, reducing the negative effects of buildings, and designing them in ways that are capable of dealing with environmental conditions and responding to changes around them. The use of natural resources and renewable energies, site planning, and the orientation of the building are the most important factors ensuring efficient performance and the quality of environmental life within the building. An indicator of a building's environmental performance is its compatibility with and level of influence on its surroundings, and the extent to which it meets design requirements that will provide users with comfort and a higher quality of life. Valuation systems play a role in environmental conservation, acting as a tool for evaluating the performance of urban projects based on certain determinants affecting the quality of overall building performance and identifying levels of energy consumption and resource depletion.

In light of Saudi Arabia's efforts towards sustainable development and the goals of its Vision 2030 programs, government efforts are focused on meeting the demands of future generations, achieving balance and economic development by conserving energy, finding alternatives to gas and oil, utilizing renewable natural resources, and developing other solutions. The Vision refers to Saudi Arabia's aspiration to be able to generate solar and wind energy at a rate of about 9.5 gigawatts by 2023 to achieve the security and 
sustainability of energy and environmental protection in the kingdom. It also addresses the use of natural thermal energy from the Earth's core, as well as the transformative energy resulting from waste exploitation to produce fuel and electric energy (Renewable Energy, 2020).

Within the framework of these efforts, we seek to study the environment, its concepts, and components, in addition to environmental performance and the elements affecting buildings, to contribute to improving the quality of the internal environment of buildings. To achieve comfort and psychological satisfaction for humans in the space, there needs to be a balance between the body, the different environments within the building, and the constantly changing climatic conditions. All of these are achieved by determining the thermal efficiency of the building, and the relationship between the design of the building and its thermal changes, while achieving reductions in energy consumption by taking advantage of the available natural resources.

This paper provides an empirical analysis of several global environmental performance assessments: Leadership in Energy and Environmental Design (LEED), enterprise, the Building Research Establishment Environmental Assessment Method (BREEAM), and the Pearl Rating System (PRS). It reviews the assessment areas of each system, comparing them, to propose a new system that is appropriate for the assessing local buildings in terms of their performance and the extent to which they attain sustainable development by reducing the attrition of natural resources and improving the quality of the indoor environment.

\section{THE ENVIRONMENT:}

Environmental science began to develop in the late 1960s when a qualitative leap was made in many fields. As a result, several international and regional books, articles, and other bodies of work were published concerning the environment, its elements, and problems (Al-Hasan, 2019). 


\subsection{Concept of the Environment:}

Defining the term "environment" is difficult because of the multiplicity of concepts associated with it, and its many influences on social, natural, human, economic, cultural, physical, and other aspects. Its meaning is related to the nature of the relationship between the environment and its users. The concept of the environment is treated with respect to existing human activities, such as the natural environment, the agricultural environment, the industrial environment, and so on. However, the definition of the term has now changed and depends on the context in which it is used (Labidi, 2015, p. 6-7).

In Arabic, the "environment" is said to be what man (generically speaking) has assumed in terms of the status of any place concerning descent and solutions. The environment is the place of residence, home, ocean, state, and the body in which man lives. The linguistic meaning of the environment is defined as the place or habitat where a person lives, encompassing different circumstances. This definition relates to a meaning with geographical scope and has certain features, such as the terrain and climate, and the range of available resources and the possibilities they offer (Al-Kahal, 2011, p. 223). In English, the term "environment" (Environment) expresses the conditions and variables concerning the environment that affect the processes of growth and development. The same term is used to express the natural conditions in which a person lives (air, water, land), and the place surrounding a person and influencing his/her feelings, attitudes, and ideas (Dir, 2014, p. 22). The French concept of the environment shares with English the notion of natural conditions (air, water, land) and the living organisms (animals, plants) present within it. However, in French, the term also refers to physical, chemical, biological, physical, natural, or artificial components and all man-made installations (Lankoande, 2005).

Ecology is another term related to the environment that was coined by the scholar Henry Thoreau and has been taken up, but he did not elaborate on it in terms of its meaning or dimensions. The term derives from two Greek words, oikos, which means at sunset, home, 
homeland, and logos, which means science. Thus, the basic term means earth science. In 1866, the German scientist Ernest Haeckel used the term ecology to denote the nature of the relationship between living organisms and the environment in which humans live (Dir, 2014, p. 23).

There are many definitions of the term environment that work with the nature of this study. For example, (Labidi 2015, p. 9) defines it as the medium in which living organisms live and draw their food in a reciprocal relationship. The environment is also defined as the place where man carries out the activities of living and all the living organisms around him with which he coexists. It is the spatial zone in which a human being exists, with both natural and human phenomena that he is affected by and affects. In addition, the environment includes all biological elements (visible and invisible organisms) and non-biological elements (water, air, and soil) that directly or indirectly affect human beings.

Dir (2014, p. 23) defines the environment as "the natural and chemical factors surrounding a living organism." This definition includes natural factors: water is water (rivers and seas), air, food, land, wastes, weather factors (wind, rain, etc.), natural observations (thunder, lightning), disasters (earthquakes, hurricanes, etc.), light, radiation, and all living organisms contained in the biological environment. It also defines the environment as the physical and biological system in which man and other living organisms coexist in an integrated and complex web that includes all interdependent and interrelated elements.

\subsection{Environmental Components:}

The components of the environment differ in nature, some being considered natural and some considered artificial or constructed. Natural elements are all those that are pre-existing and man has had no hand whatsoever in creating, but are the handiwork of God the Almighty. Thus, the natural elements include the resources and the components of life, such as water, air, forests, and land, as well as all living things, including man, animals, and plants, created in their natural state by God and without human intervention. The natural 
elements help people carry out their assigned roles and meet their basic needs and requirements. They can be classified into three main categories: non-living natural elements (air, water, dust), and living elements, both plant and animal (Abdel Ghani, 2013, p. 15).

In contrast, the artificial, constructed (or industrial) elements comprise those created by man over time as a result of his interaction with the environment surrounding him and the modification of its components to adapt and utilize them in his service, to meet his needs, and achieve well-being in his life. It incorporates the infrastructure built by man and the institutions established, including residential and industrial areas. It comprises the constructing of centers, institutes, schools, and others, as well as all urban components, such as roads, airports, ports, factories, cars, trucks, etc. (Abdel Ghani, 2013, p. 16).

\subsection{Problems Affecting the Built Environment:}

The adverse reactions of man's interaction with the environment surrounding him have resulted in the emergence of some serious environmental problems threatening the survival of environmental elements, indeed life itself. Critical among these are environmental pollution and the depletion of natural resources, which will affect the sustainability and survival of future generations (Labidi, 2015, p. 23).

Pollution is one of the most important issues facing the environment and is a serious threat to its elements. In particular, environmental components, especially natural, are suffering from pollution due to development in many industrial and technological fields, (Labidi, 2015, p. 23). Environmental pollution is defined as quantitative changes in living and non-living environmental components such that the environment cannot absorb or control them. These changes result from intentional and unintentional activities that are harmful to one or more natural elements. Put in other terms, pollution comprises changes in the organic, thermal, biological, and radiological characteristics of the components of the environment.

The other major threat is environmental resource depletion. Increasing pressure on natural resources, especially non-renewable, 
through usage increases their value, but over time they will eventually disappear. Exploiting such resources also impacts the balance of the ecosystem, resulting in significant risks. Fear of depleting natural resources has led to the development of new trends with a view to achieving environmental sustainability. In construction, sustainability is an approach to managing the design of buildings aimed at reducing negative environmental impacts, securing the availability of existing resources to meet needs, and ensuring their existence for future generations (Al-Attar, Mubarak, \& Al-Jumaili, 2018, p. 263). With the emergence of many problems related to the scarcity and depletion of natural resources, sustainability has become an important issue in their management, and urban and building design policies. In particular, there is increased interest in the contribution of sustainability issues to development, economic improvements, environmental protections, reducing energy use, and the optimal use of natural and renewable resources. Several concepts related to sustainable building design have emerged, such as sustainable cities, and other concepts that form the overall framework of sustainability (Al-Baaj, 2018, p. 3).

\section{ENVIRONMENTAL PERFORMANCE:}

\subsection{The Environmental Performance Concept:}

The environmental performance of a building concerns the extent of its response and adaptation to the constantly changing environmental and climatic conditions around it through its design and architectural elements (Muhammad, 2016, p.16). The concept also refers to operating in a responsible manner towards the environment through optimal utilization of resources, minimization of waste, and disposal of waste in a safe manner, as well as the efficiency in the building's use of energy and minimizing the negative effects of the building materials used on the environment (Bakhit, 2018, p. 95). 


\subsection{Problems Affecting the Built Environment:}

The adverse reactions of man's interaction with the environment surrounding him have resulted in the emergence of some serious environmental problems threatening the survival of environmental elements, indeed life itself. Critical among these are environmental pollution and the depletion of natural resources, which will affect the sustainability and survival of future generations (Labidi, 2015, p. 23).

Pollution is one of the most important issues facing the environment and is a serious threat to its elements. In particular, environmental components, especially natural, are suffering from pollution due to development in many industrial and technological fields, (Labidi, 2015, p. 23). Environmental pollution is defined as quantitative changes in living and non-living environmental components such that the environment cannot absorb or control them. These changes result from intentional and unintentional activities that are harmful to one or more natural elements. Put in other terms, pollution comprises changes in the organic, thermal, biological, and radiological characteristics of the components of the environment.

The other major threat is environmental resource depletion. Increasing pressure on natural resources, especially non-renewable, through usage increases their value, but over time they will eventually disappear. Exploiting such resources also impacts the balance of the ecosystem, resulting in significant risks. Fear of depleting natural resources has led to the development of new trends with a view to achieving environmental sustainability. In construction, sustainability is an approach to managing the design of buildings aimed at reducing negative environmental impacts, securing the availability of existing resources to meet needs, and ensuring their existence for future generations (Al-Attar, Mubarak, \& Al-Jumaili, 2018, p. 263). With the emergence of many problems related to the scarcity and depletion of natural resources, sustainability has become an important issue in their management, and urban and building design policies. In particular, there is increased interest in the contribution of sustainability issues to development, economic improvements, environmental protections, reducing energy use, and the optimal use of natural and renewable resources. 
Several concepts related to sustainable building design have emerged, such as sustainable cities, and other concepts that form the overall framework of sustainability (Al-Baaj, 2018, p. 3).

\section{ENVIRONMENTAL PERFORMANCE:}

\subsection{The Environmental Performance Concept:}

The environmental performance of a building concerns the extent of its response and adaptation to the constantly changing environmental and climatic conditions around it through its design and architectural elements (Muhammad, 2016, p.16). The concept also refers to operating in a responsible manner towards the environment through optimal utilization of resources, minimization of waste, and disposal of waste in a safe manner, as well as the efficiency in the building's use of energy and minimizing the negative effects of the building materials used on the environment (Bakhit, 2018, p. 95).

Buildings characterized by effective environmental performance are those capable of addressing economic, social, and environmental dimensions and impacts by applying the principles of design, construction, and sustainable and environmentally friendly operation, which leads to savings in the operational energies of the buildings, improved thermal and acoustic comfort, better safety in terms of the building users' health, and reduced negative impacts on the environment. The application of sustainability standards increases the environmental performance of buildings, as they become more energy efficient and effective on economic and social dimensions. These buildings are characterized by a sustainable design that provides a comfortable, safe, healthy, and high-quality living environment operating at a high level of environmental efficiency (Ren, 2013, p. 7).

Sustainable design encompasses all new design and construction tools that take into account environmental problems and challenges to the permanence of natural resources. Sustainable design is one of the modern trends in design, taking upon itself the relationship between the built environment and the natural environment. The intention is to design, implement, and manage the built environment 
using advanced methods and means, aiming to reduce negative impacts on the natural environment, reduce maintenance and operating costs, and provide a comfortable and safe living environment. As Al-Baaj (2018, p. 3) points out, the factors that led to the crystallization of the concept of sustainability in the building industry are the same as those that led to the emergence of the concept of sustainable development in relation to various social, economic, and environmental aspects. Environmental sustainability can be achieved by preserving natural resources, managing them well, and developing them to preserve them for future generations. The benefits of environmental sustainability include reducing the rates of all kinds of pollution, reducing the harmful gases emitted as carbon dioxide, reducing the volume of waste from non-renewable energy consumption, improving air and water quality, and protecting biodiversity and various ecosystems, as well as increasingly using renewable resources, helping to conserve natural resources and preserving the environment (Cavalcanti \& Cândido, 2016, p. 8).

\subsection{Criteria for Assessing the Environmental Performance of Buildings:}

A number of criteria are used to measure the environmental performance of a building, including the site on which it is located, and how it manages the resources and energies used. These criteria are addressed in the following paragraphs.

Location of the building and the land on which it is built, This standard includes protecting the site and respecting its privacy by locating the building on the site in a way that does not change the features of the site and does not lead to any radical changes in it. The architectural design must take into account the climatic conditions of the site, preserving its environmental components, achieving integration between the design and environment, and mitigating any potential negative effects of the building on the site. This is done during the study of the site, aiming to take advantage of all possibilities, such as deciding the orientation of the building and employing strategies for dealing with the environment to attain coexistence and integrate the building as a part of it (Al- Baaj, 
2018 , p. 4). This axis also concerns reducing the risks of pollution and high temperatures resulting from replacing vegetation with concrete masses, in addition to choosing the site to meet environmental requirements and achieve the optimal use of renewable resources, such as the sun, shade, etc. Several environmental studies concerned with the environmental performance of buildings have recommended raising the level of vegetation around the buildings, which leads to improvements in the internal atmosphere, providing shade and clean air, and keeping the temperatures inside the building within the range of thermal comfort throughout the different seasons (Hussain, 2011, p. 1).

Creative innovative design, this axis aims to deal with the natural environmentand adapt it to improve the performance of the building by using the building elements themselves to achieve this. This axis includes two main points. First, it aims to design buildings in an integrated manner, exploiting the nature of their design and making their attributes useful, such as designed windows and openings efficiently to optimize the use of natural lighting (daylight), thus reducing the consumption of electrical energy. Natural ventilation can also be used by exploiting the air currents resulting from differences in temperature and air pressure, leading to a reduction in the energy loads used for cooling. To heat the building and water, solar energy can be exploited as the sun's rays are a source of thermal energy, and this will also work with the natural lighting system to reduce the electrical load resulting from the use of industrial lighting. Second, it considers the outer envelope of the building, which separates the inside and outside of the building, and includes doors, windows, ceilings, and walls. Theseelements can be designed to reduce energy consumption and enhance the environmental performance of the building through thermal insulation. This saves energy, improves the air quality inside the building, and reduces the amount of heat transfer and air leakage, leading to the rationalization of energy consumption and enhanced thermal comfort. The windows and glass used will be of a quality that controls the temperature of the building, aided by using shading, solar blinds, and sealing insulation. Double glazing can also be used and the space between the glass layers can be filled 
with inertgases that prevent heat transfer (Hussain, 2011, pp. 2-3).

Effective management and conservation of energy sources, Buildings witheffective environmental performance are designed to reduce the use of non-renewable energy, such as fuel and gas, and rely more on renewable resources, such as the sun and natural air, to undertake heating, cooling, and lighting operations. This is accomplished through design methods that work to conserve energy and raise the efficiency of buildings, the most important being the use of solar energy for heating and cooling systems, incorporating natural ventilation systems, and ensuring the correct orientation of the building and windows (Al-Baaj, 2018, p. 4).

Water resource management, This axis concerns effective water usage, achieved through rationalizing water consumption, reducing waste, and using gray water from the bathroom sink and shower for washing machines, air conditioners, and refrigerators in some cases, as well as irrigation, cooling, and industrial purposes in toilets, fire extinguishers, etc. It also exploits water springs and the collect of rainwater from roofs, which is stored in special tanks and used for irrigation and other purposes appropriate to the characteristics of this water (Hussain, 2011, pp. 3-4).

Waste and resource management, this axis is based on the principle of reducing the use of non-renewable resources in buildings, and moving towards approaches that are based on reusing the buildings themselves or some of their components as resources for other buildings (Al-Baaj, 2018, p. 4). This can reduce the waste resulting from maintenance and operations, and utilizing materials such as iron, aluminum, cardboard, glass, and other recyclable materials. The waste resulting from construction and demolition operations can also be reduced by reusing parts of the old building and in new buildings where possible (Hussain, 2011, p. 4).

Achieving a high quality internal and external environment, Good environmental quality can be achieved by fulfilling all the requirements that ensure the buildings and construction systems do not emit any toxic gases, either in the internal or external environment, as well as providing means of renewing the air inside 
the building on an ongoing basis (Al-Baaj, 2018, pp. 4-5). The internal environment of the building can be improved by ensuring continuous ventilation and exposure to the sun's rays, controlling the temperature to protect from humidity and mould, which may cause disease, closing openings for sanitary and electrical installations, and providing ventilation for exhaust fumes in facilities and services. It is also possible to avoid the use of industrial materials that can lead to the emission of toxic compounds, exploiting natural lighting and sunlight to create a comfortable and healthy environment inside the building (Hussain, 2011, pp. 4-5).

Natural ventilation and internal air quality, Natural ventilation is the process of replacing the air inside spaces and with air from the outside by natural methods without the intervention of techniques that require electrical energy. Natural ventilation is one of the factors that helps control climatic conditions, improves the efficiency of a building's environmental performance, and provides a healthy environment with high environmental quality. Natural ventilation affects the level of comfort and improves the performance of the building, either indirectly or directly through its effect on people themselves and their sense of thermal equilibrium based on the regulation of thermal processes and the degree of internal humidity (Shaheen, 2017, p. 7).

Natural ventilation is important for indoor air quality achieved by constantly changing the air. This provides thermal comfort in a building, reducing humidity and achieving an appropriate cooling temperature so that when the body temperature is higher than the ambient temperature, the body can lose heat and not experience the effects of sweating (Shaheen, 2017, pp. 9-10).

The movement of air inside the building can be controlled through the building design, directing opening using the elements of site coordination and the distribution of trees, and studying the orientation of the building in terms of the movement of the sun and the direction of wind. The design factors include the area and size of openings and their orientation, transverse ventilation, the vertical 
location of openings, the method of opening windows, the general layout of the site, and the design of interior partitions (Shaheen, 2017, p. 9).

Natural lighting (luminance), Natural lighting is one of the basic components of the design process, and is one that has been used continuously for aesthetic purposes in architectural designs and to provide appropriate levels of lighting. The design takes into account quantitative and qualitative considerations and the distribution of light in proportion to the use of the space (Salim, 2008, p. 130).

\subsection{Design Elements Affecting the Quality of Building Performance:}

The environmental performance of a building is affected by a number of factors that determine the quality of life inside it and how it deals with the environment, including the properties of the building materials used that contribute to heat loss and gain, the occupancy rate, the devices and equipment considered to be sources of heat emitted internally, and finally the design variables that affect thermal performance. These include a number of factors detailed by Zoroub (2014, p. 30) addressed in the following paragraphs.

\section{Design variables}

- Site planning: The planning of relationships (the distribution of building blocks, their heights, and the distances between them) plays a major role in determining the effect of incident solar radiation and air flow around buildings, and both the land use and the blocks within it must be planned in a way that helps to change the air continuously and reduce the temperature. 
- Vegetation: The amount of flora and number of trees planted around the building will affect the quality of the internal environment. Plants can act as windbreaks and improve air quality while reducing solar radiation by $8.6 \%$, thus reducing the amount of energy consumed in cooling and heating operations by $25 \%$.

- Building shape: The shapes of buildings can be designed to reduce energy consumption, that is, to gain the largest amount of energy in winter and less in summer. The shape of the building plays a role in determining the area exposed to external conditions and affects the quantities of heat gain and loss.

- Building envelope: The outer part of the building, which separates the external and internal environments, is responsible for protecting internal spaces from the influence of the external environment and its conditions. The envelope includes ceilings, windows, and walls, and must be designed with due regard to regulatory requirements and conditions so that the design conforms to standards.

- Shading devices: Shading devices are used to regulate the entry of solar rays into a space and how air flows into internal spaces. These include architectural projections, window shutters, and nets.

- Properties of building materials, The characteristics of the materials used in the construction of the building and the design control the heat transfer process. Considerations include thermal resistance, thermal transfer, and thermal conductivity, and the materials chosen should be within specifications that reduce the amount of heat gain and loss (Zarib, 2014, p. 30.)

- Building occupancy, the occupancy rate relates to the thermal loads resulting from lighting, equipment, and devices inside the building, and the type and intensity of work and activities undertaken in the spaces by the people within them, as the human body works to lose excess heat to the surroundings to achieve thermal balance (Zarib, 2014, p. 30.) 


\section{Global evaluation systems for environmental performance efficiency:}

Evaluation systems are defined as methods for assessing the performance of urban projects and the determinants that affect their performance. Evaluation systems aim to enable the design of projects that achieve a better level of comfort for the user and reduce the negative effects of buildings on the environment. There are many global evaluation systems, the most important and best know are addressed below.

\subsection{Leadership in Energy and Environmental Design (LEED):}

Leadership in Energy and Environmental Design (LEED) is considered one of the most important systems used in evaluating buildings and strengthening the foundations of sustainable design. The American Green Building Association began the program in 1993, and the U.S. Green Building Council succeeded in issuing the first version by 1998. The evaluation awards points in nine basic areas (USGBC, 2020): 1.Integrative process; 2.Location and transportation; 3.Sustainable sites; 4.Water use efficiency; 5.Outer envelope and energy; 6.Materials and resources; 7.Indoor environment quality; 8.Innovation; 9.Regional priority. There is a specific focus on evaluation points in the following areas:

- Outer envelope and energy: 32 points

- Indoor environment quality: 16 points

- Site and transportation: 16 points 


\subsection{The Building Research Establishment Environment Assessment Method (BREEAM):}

The Building Research Establishment Environment Assessment Method (BREEAM) is another highly important global system used in the environmental assessment of buildings. Established in 1988, it was the first performance evaluation system and method in the world to evaluate buildings environmentally. It uses weighted percentages to evaluate buildings (BREEAM, 2018, p. 1) in the following areas: 1. Health and well-being; 2. Energy; 3. Transportation; 4. Water; 5. Materials; 6. Waste;

7. Environment and land use; 8. Pollution, The greatest focus in on the following areas:

- Energy: $16 \%$

- Materials: $15 \%$

- Health and well-being: $14 \%$

\subsection{Pearl Rating System (PRS):}

The Pearl Rating System (PRS) is the first measure to address building sustainability in the Arab region and is similar to the LEED system, but updated by the Abu Dhabi Urban Planning Council to match the context and culture of Abu Dhabi. It combines the awarding points and percentages in the following areas: 1 . Integrated development process; 2. Natural systems; 3. Buildings suitable for life (internally and externally); 4. Water importance; 5.Energy sources; 6.Material management; 7.Experience and training for innovation. The greatest focus is on the following areas:

- Energy sources: 44 points, $24 \%$

- Water importance: 43 points, $23 \%$

- Material management: 28 points, $16 \%$ 


\subsection{Analytical Comparison of Environmental Performance Assessment Systems:}

Reviewing the data for each system, the evaluation areas, and the number of points, it is possible compare the baselines for each of the systems described above: LEED, BREEAM, and PRS. Table 1 presents the key aspects of each system in terms of the main and sub-evaluation areas, the points awarded, and the evaluation levels.

Table 1 - Comparison of systems: focal areas, points, and levels of evaluation (Source: Authors' own elaboration)

\begin{tabular}{cccc}
\hline & LEED & BREEAM & PRS \\
\hline Main areas & 9 & 10 & $\mathbf{8}$ \\
\hline Sub domains & 67 & 107 & $\mathbf{8 6}$ \\
\hline & & & $\mathbf{5}$ \\
\hline $\begin{array}{c}\text { Evaluation } \\
\text { levels }\end{array}$ & 4 levels & 6 levels & $\mathbf{1 7 7}$ \\
\hline $\begin{array}{c}\text { Evaluation } \\
\text { points }\end{array}$ & 110 & 110 & \\
\hline
\end{tabular}

Table 2 shows a comparison between the main evaluation areas of each system and the number of points per area. The points for the evaluation have been converted into percentage points to facilitate comparison of similarities between them and the impact of each component concerning the total for each area. 
Table 2 - Comparison of systems in terms of similarities and differences in areas (Source: Authors' own elaboration)

\begin{tabular}{|c|c|c|c|c|c|c|}
\hline \multirow{2}{*}{$\begin{array}{c}\text { Evaluation } \\
\text { areas }\end{array}$} & \multicolumn{2}{|c|}{ LEED } & \multicolumn{2}{|c|}{ BREEAM } & \multicolumn{2}{|c|}{ PRS } \\
\hline & Points & $\begin{array}{l}\text { Basic } \\
\text { item }\end{array}$ & Points & $\begin{array}{c}\text { Basic } \\
\text { item }\end{array}$ & Points & $\begin{array}{c}\text { Basic } \\
\text { item }\end{array}$ \\
\hline $\begin{array}{c}\text { Integrative } \\
\text { process }\end{array}$ & $1 \%$ & $\checkmark$ & 0 & $\mathrm{x}$ & $7 \%$ & $\checkmark$ \\
\hline Management & 0 & $\mathrm{x}$ & $11 \%$ & $\checkmark$ & 0 & $\mathrm{x}$ \\
\hline $\begin{array}{l}\text { Location and } \\
\text { transportation }\end{array}$ & $14 \%$ & $\checkmark$ & $10 \%$ & $\checkmark$ & 0 & $\mathrm{x}$ \\
\hline $\begin{array}{l}\text { Sustainable/ } \\
\text { external sites }\end{array}$ & $9 \%$ & $\checkmark$ & 0 & & $7 \%$ & $\checkmark$ \\
\hline $\begin{array}{c}\text { Water } \\
\text { efficiency }\end{array}$ & $10 \%$ & $\checkmark$ & $7 \%$ & $\checkmark$ & $23 \%$ & $\checkmark$ \\
\hline $\begin{array}{l}\text { External } \\
\text { atmosphere } \\
\text { and energy }\end{array}$ & $30 \%$ & $\checkmark$ & $16 \%$ & $\checkmark$ & $24 \%$ & $\checkmark$ \\
\hline $\begin{array}{l}\text { Materials and } \\
\text { resources }\end{array}$ & $12 \%$ & $\checkmark$ & $15 \%$ & $\checkmark$ & $16 \%$ & $\checkmark$ \\
\hline $\begin{array}{c}\text { Quality of } \\
\text { internal } \\
\text { environment, } \\
\text { health, and } \\
\text { well-being }\end{array}$ & $15 \%$ & $\checkmark$ & $14 \%$ & $\mathrm{x}$ & $14 \%$ & $\checkmark$ \\
\hline $\begin{array}{l}\text { Natural } \\
\text { systems }\end{array}$ & 0 & $\mathrm{x}$ & 0 & $\mathrm{x}$ & $7 \%$ & $\checkmark$ \\
\hline $\begin{array}{c}\text { Regional } \\
\text { priority }\end{array}$ & $5 \%$ & $\checkmark$ & 0 & $\mathrm{x}$ & 0 & $\mathrm{x}$ \\
\hline Waste & 0 & $\mathrm{x}$ & $6 \%$ & $\checkmark$ & 0 & $\mathrm{x}$ \\
\hline $\begin{array}{c}\text { Land use and } \\
\text { environment }\end{array}$ & 0 & $\mathrm{x}$ & $13 \%$ & $\checkmark$ & 0 & $\mathrm{x}$ \\
\hline Pollution & 0 & $\mathrm{x}$ & $13 \%$ & $\checkmark$ & 0 & $\mathrm{x}$ \\
\hline Innovation & $4 \%$ & $\checkmark$ & $10 \%$ & $\checkmark$ & $2 \%$ & $\checkmark$ \\
\hline
\end{tabular}

As shown in Tables 1 and 2, there are several areas that are similar across all systems, whereas some areas vary according to the country and its requirements. The most important areas are clear, being those that are repeated in all systems. 


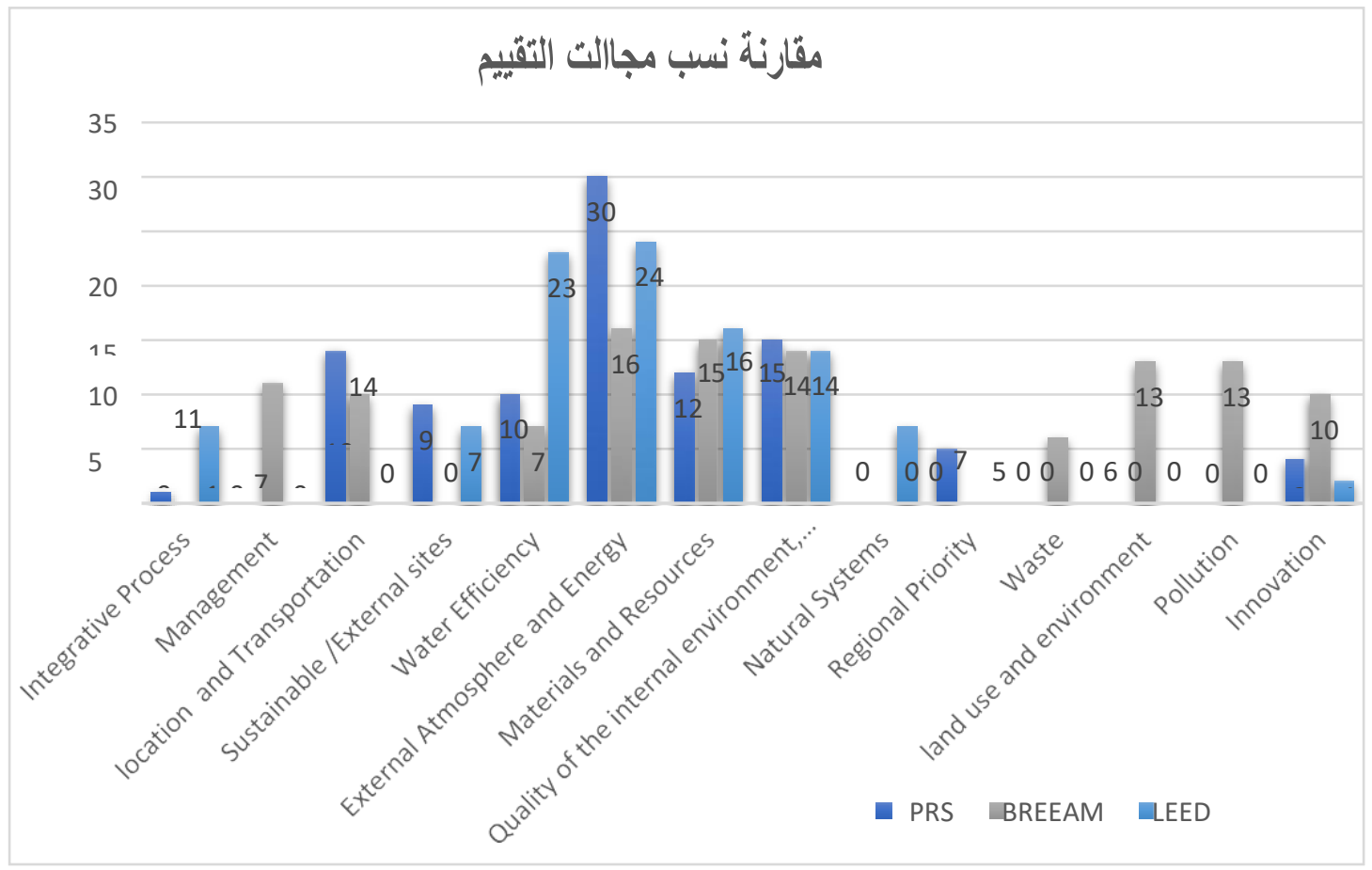

Fig.1. Comparison of systems in terms of rating ratios in evaluation areas (Source: Authors' ownelaboration)

From the comparisons in Table 2 and Fig. 1, the following points are clear:

- The primary interest in all systems focuses on the external atmosphere and the energy of the building, achieving the highest percentages to reduce energy consumption as much as possible.

- There second priority is materials and resources with a view to achieving the highestefficiency in terms of the materials used.

- The systems then focus on the quality of the indoor environment.

- Fourth, they consider the internal air quality, thermal comfort, and visual comfort for users inside the building.

As noted above, the evaluation systems vary in terms of the ratios for each evaluation area, owing to the significant differences between the domestic circumstances of each country issuing the systems. 


\subsection{Evaluation System Suitable for Building Facades in Saudi Arabia:}

Based on the analytical comparison of existing systems, this paper proposes a system that is appropriate for buildings in a local area in Saudi Arabia, especially mobile facades. Table 3 presents the mandatory items for assessment of the quality of building performance based on the facades. These evaluation areas were chosen for their importance and contribution to conserving energy and resources, and improving the internal performance of buildings. The evaluation targets the building's outer envelope due to its direct effects given the surrounding environmental conditions and its protection of internal spaces.

Table 3 - Proposed items for the evaluation system (Source: Authors' own elaboration)

\begin{tabular}{cll}
\hline Evaluation areas & $\begin{array}{l}\text { Evaluation objectives } \\
\text { (Mandatory system } \\
\text { lines) }\end{array}$ & Percentage \\
\hline Integrative process & $\begin{array}{l}\text { Develop overall strategy } \\
\text { and design guide for } \\
\text { mobile buildings }\end{array}$ & $2 \%$ \\
Sustainable sites & $\begin{array}{l}\text { Choose locations that are } \\
\text { appropriate for the project } \\
\text { and use }\end{array}$ & $6 \%$ \\
& $\begin{array}{l}\text { Orientate the building to } \\
\text { take advantage of natural } \\
\text { systems }\end{array}$ & \\
\hline External atmosphere and power & $\begin{array}{l}\text { Minimum energy use } \\
\text { Reduction of greenhouse } \\
\text { gas emissions } \\
\text { Provision of alternative } \\
\text { energy by building casing }\end{array}$ & $32 \%$ \\
& $\begin{array}{l}\text { Selection of high- } \\
\text { sustainability materials } \\
\text { Selection of removable } \\
\text { materials and guidance }\end{array}$ & $19 \%$ \\
\hline
\end{tabular}




\begin{tabular}{|c|c|c|}
\hline Internal environmental quality & $\begin{array}{l}\text { Providing health, well- } \\
\text { being, and safety } \\
\text { Providing visual and } \\
\text { thermal comfort } \\
\text { Improving air quality and } \\
\text { lighting }\end{array}$ & $22 \%$ \\
\hline Natural systems & $\begin{array}{l}\text { Making use of available } \\
\text { natural resources }\end{array}$ & $6 \%$ \\
\hline Innovation & $\begin{array}{l}\text { Innovation while } \\
\text { preserving national } \\
\text { culture and identity }\end{array}$ & $12 \%$ \\
\hline
\end{tabular}

\subsection{Points Distribution on the Proposed Evaluation Form:}

Having analyzed the existing systems and determined the most important areas of evaluation that fit the study, Table 4 presents the criteria for sustainable buildings, showing mandatory items (M), sub-items, points and percentages (assuming a total number of points $=140$ ) for each domain assessed. Once the requirements for mandatory items have been met, points will be distributed for the sub-items to achievethe total for each of the main evaluation areas.

\subsection{Proposed System Evaluation Levels:}

Having developed the proposed environmental performance evaluation system, and established points for each field (total 140 points) and their percentages (total 100\%), the classifications for competency certificates that will be issued are defined based on the points acquired. As shown in Table 5, there will be four levels, starting with the minimum level certificate (56-75 points), then the intermediate level certificate (76-97 points), then the high level certificate (98-118 points), and finally the superiorlevel certificate (119-140 points) as the highest classification. 
Table 5 - System evaluation levels for the classification of certificates (Source: Authors' ownelaboration)

\begin{tabular}{lcc}
\hline \multicolumn{2}{c}{ SYSTEM EVALUATION LEVELS } & \\
\hline \multicolumn{1}{c}{ Classification } & Percentage & Number of points \\
Minimum level certificate & $40-54$ & $56-75$ \\
\hline Intermediate level certificate & $55-69$ & $76-97$ \\
\hline High level certificate & $70-84$ & $98-118$ \\
\hline Superior level certificate & $85-100$ & $119-140$ \\
\hline
\end{tabular}

\section{FINDINGS AND RECOMMENDATIONS:}

This paper has presented a theoretical study of the environment and the principles of environmental performance to define the quality of the internal environment of buildings and identify the elements affecting them. Furthermore, through a comparative analysis of global environmental performance appraisal systems, not undertaken in previous research, the paper contributes to knowledge by creating a new system of environmental measurement which is compatible with the area of study. This system draws on the results of the comparison and conclusions concerning the most important components of environmental evaluation to assess buildings and make optimal use of them for environmental conservation. The key points are as follows: 
1. Evaluation should aim to protect and preserve the environment, as this is the medium in which human beings live.

2. The analysis highlights the importance of reducing resource depletion and conserving resources by finding solutions and alternatives to preserve the environment and achieve sustainable development.

3. The environmental performance of a building is one of the indicators that show the extent of the building's compatibility with the surrounding environment, attaining the users' comfort while enhancing the quality of the internal environment.

4. An assessment system for environmental performance commensurate with the local environment needs to be proposed due to the differences in levels of each field in different evaluation systems linked to the countries endorsing them.

\section{Based on the study, several recommendations are made.}

\section{Recommendations for government institutions}

- Governments need to raise awareness of the factors affecting the quality of building performance and those that protect them from climatic conditions.

- It is necessary to enforce regulations, laws, and design standards to preserve the environment.

- Agencies and institutions should be encouraged to develop building systems and improve their performance.

- Environmental performance evaluation forms should be applied to buildings.

- Rewards should be provided for obtaining a certificate of competence.

- Part of the state budget should be allocated to improving environmental quality and achieving sustainable development. 


\section{Recommendations for designers}

- Attention should be paid to environmental design and the application of design standards listed by government institutions.

- The design stage should contribute to reducing costs while obtaining the highest internal quality efficiency.

- Environmental performance evaluation forms should be applied to projects during their implementation and operation.

\section{Recommendations for society}

- The community and university students need to be educated about the importance of the environment and ways to preserve it.

- The concept of environmental performance, methods of implementing it, and ways of evaluating it should be explained to students.

- The culture of sustainable development should be spread by disseminating information on the importance of evaluating the environmental performance of buildings, and ways of improving the quality of the internal environment.

- It is necessary to target prospective builders, whether of private homes or buildingswith other uses.

\section{FUTURE STUDIES}

The effectiveness and efficiency of the proposed system will be demonstrated in future studies by studying examples and experiences of previous projects and applying the system to them to determine their efficiency. A mobile building cover model will also be designed and evaluated to test the feasibility of the proposed system. Mobile interfaces will be developed using computer-aided design and an impact study will be conducted on reducing the thermal gain of buildings. In addition, future work will consider the response of the interface to take advantage of 
external factors and renewable energy sources, converting them into electrical energy that will benefit the building and enable it to operate, affecting the use of the facility in general and the performance of the moving envelope in particular.

\section{References}

- Renewable energy. (21 December 2020). Recovered from King Abdullah City for Atomic andRenewable Energy: https://www.energy.gov.sa/ar/FutureEnergy/RenewableEnergy/P ages/default.aspx

- Cavalcanti, R.F., \& Cahn Dido, G.A. (2016). ENERGY SUSTAINABILITY: Proposed indicators and their contributions to the adoption of more effective policies and actions for the energy sector. Holos Journal, 8(32), 3-23.

- Ren, J. (2013). High-Performance Building Design and Decision-Making Support for Architects in the Early Design Commas. Stockholm, Sweden: Kungliga Tekniska Högskolan, the Royal Institute of Technology.

- Yambilla Florent Lankand. (2005), the environment. Limoges: Universal Lies. 